\title{
Gas Threshold Pressure Test Performed at the Mont Terri Rock Laboratory (Switzerland): Experimental Data and Data Analysis
}

\author{
J. Croisé' , G. Mayer' ${ }^{1}$, P. Marschall ${ }^{2}$, J.M. Matray ${ }^{3}$, T. Tanaka ${ }^{4}$ and P. Vogel ${ }^{5}$ \\ 1 Colenco Power Engineering AG, Groundwater Protection and Waste Disposal, Täfernstr. 26, CH-5405 Baden - Switzerland \\ 2 NAGRA, National Cooperative for the Disposal of Radioactive Waste, Hardstr. 73, 5430 Wettingen - Switzerland \\ 3 IRSN, Institut de radioprotection et de sûreté nucléaire, avenue du Général Leclerc, BP 17, 92262 Fontenay-aux-Roses - France \\ 4 Obayashi Corporation, Konan 2-15-2, Minato-ku, Tokyo 108-8502 - Japan \\ 5 BGR, Bundesanstalt für Geowissenschaften und Rohstoffe, Stilleweg 2, 30655 Hannover - Germany \\ e-mail: jean.croise@colenco.ch - gerhard.mayer@colenco.ch - marschall@nagra.ch - jean-michel.matray@irsn.fr \\ obayashi@grimsel.com - p.vogel@bgr.de
}

\begin{abstract}
Résumé - Essais d'injection de gaz dans les argiles à Opalinus du laboratoire souterrain du Mont Terri (Suisse) : données et interprétation - La migration de gaz dans les roches argileuses est un sujet d'intérêt dans le cadre de différents types d'exploitation du sous-sol : que ce soit par exemple dans le domaine du stockage de gaz naturel, de la séquestration du $\mathrm{CO}_{2}$, comme éponte imperméable d'un aquifère, ou dans le domaine du stockage de déchets. Une analyse quantitative de la migration de gaz dans ces milieux à très faible perméabilité nécessite l'estimation des propriétés physiques de l'écoulement. Au laboratoire souterrain du Mont Terri (Suisse), dans les argiles à Opalinus, une roche sédimentaire jurassique, une série de tests hydrauliques et d'injection de gaz a été conduite en forages d'expérimentation. Leur but était en particulier de déterminer les propriétés de transfert des gaz dans cette roche. Cet article présente les résultats d'une campagne de tests (sollicitations de type essai hydraulique classique et test d'injection de gaz et récupération de pression de longue durée), conduite dans la roche « intacte », c'est-à-dire non perturbée mécaniquement par le creusement des galeries. Il présente une interprétation détaillée des tests reposant sur l'ajustement des données expérimentales au moyen d'un logiciel de simulation numérique biphasique (eau/gaz) de l'écoulement en milieu poreux (TOUGH2/iTOUGH2). Par analyse séquentielle, il a été possible d'obtenir un set de paramètres hydrauliques mono- et diphasiques cohérent sur l'ensemble de l'expérimentation. L'utilisation d'informations additionnelles et indépendantes sur les caractéristiques pétrophysiques de la roche (porosité et pression capillaire) a permis de mieux contraindre le problème inverse à l'étude. Bien qu'il soit difficile sur la base des différents modèles et ajustements réalisés, d'obtenir une solution unique en terme de courbe de pression capillaire et de perméabilité relative, les résultats indiquent qu'une paramétrisation classique de type Van Genuchten - Mualem serait valide. Enfin, des simulations prospectives sont présentées qui montrent que l'amélioration de la performance des essais en termes de détermination des paramètres biphasiques nécessiterait une augmentation notable de la durée de l'essai (> 1 an).
\end{abstract}

Abstract - Gas Threshold Pressure Test Performed at the Mont Terri Rock Laboratory: Experimental Data and Data Analysis - Migration of gases in argillaceous formations increasingly attracts the attention of various geoscientific disciplines for purposes like $\mathrm{CO}_{2}$ sequestration, gas storage in 
geological formations and disposal of hazardous wastes. Quantitative assessment of gas transport in such ultra-low permeability formations requires information on gas transport properties of the argillaceous formation. A series of hydro- and gas tests in boreholes was performed at the Mont Terri Rock Laboratory in Switzerland to investigate gas transport in the Opalinus Clay, an indurated clay formation of Jurassic age. This paper presents the results of a comprehensive test campaign in the shaly facies of the Opalinus Clay, comprising a "classical" hydrotest with water injections followed by pressure recovery sequences and an extended gas threshold pressure test. A detailed interpretation of both the hydraulic and gas test sequences was conducted using numerical simulations for the data analysis (software TOUGH2/iTOUGH2). In contrast to former test analyses, the sequential interpretation of the hydro- and gas test sequences provided a consistent set of single-phase hydraulic parameters and two-phase flow parameters. The use of independent information from laboratory testing (porosity, capillary pressure curves) constrained distinctly the inverse problem of parameter fitting. Discrimination between different parametric models of the relative permeability was impaired by inherent limitations of the field data due to non-ideal test conditions. Nevertheless, a classical two-phase flow type capillary pressure - relative permeability relationship based on the Van Genuchten - Mualem approach was found to be valid. A supplementary design study was conducted to optimise the test procedures to better distinguish between relative permeability models. It is shown that long term (> 1 year) injection tests are more adequate to constrain the models. This finding is important for the design of future gas threshold pressure tests in indurated clays.

\section{NOTATIONS}

$1 / \alpha$

$c_{O P A}$

$c_{t z}$

$D\left(S_{w}\right)$

$\mathrm{D}_{\mathrm{D}}\left(S_{w}\right)$

$\eta$

$f_{g}$

$f_{w}\left(S_{w}\right)$

$\gamma$

\section{$h$}

k

$k_{r, w}$

$k_{r, g}$

$k_{r w}$

$k_{\text {rnw }}$

$\mu_{w}$

$\mu_{n w}$

n

\section{$P_{a e}$}

$P_{c}$

$P_{i}$ pseudo air entry pressure for the gas phase $(\mathrm{Pa})$

rock compressibility $\left(\mathrm{Pa}^{-1}\right)$

test zone compressibility $\left(\mathrm{Pa}^{-1}\right)$

diffusion function $\left(\mathrm{m}^{2} \mathrm{~s}^{-1}\right)$

dispersion function (dimensionless)

exponent describing the pore connectivity of the porous medium (dimensionless)

multiplication factor in the relative permeability equation (dimensionless)

fractional flow for water (dimensionless)

exponent describing the pore connectivity of the porous medium (dimensionless)

length of the test interval (m)

intrinsic permeability $\left(\mathrm{m}^{2}\right)$

relative permeability of the water phase (dimensionless)

relative permeability of the gas phase (dimensionless)

relative permeability of the wetting phase (dimensionless)

relative permeability of the non-wetting phase (dimensionless)

viscosity of the wetting phase (Pas)

viscosity of the non-wetting phase (Pas)

pore size distribution index (shape factor) (dimensionless)

air entry pressure $(\mathrm{Pa})$

capillary pressure $(\mathrm{Pa})$

static formation pressure $(\mathrm{Pa})$
$\Phi \quad$ porosity (dimensionless)

$Q_{t} \quad$ total flow rate $\left(\mathrm{m}^{3} \mathrm{~s}^{-1}\right)$

$Q_{n w} \quad$ non-wetting phase flow rate $\left(\mathrm{m}^{3} \mathrm{~s}^{-1}\right)$

$Q_{w} \quad$ wetting phase flow rate $\left(\mathrm{m}^{3} \mathrm{~s}^{-1}\right)$

$r_{D} \quad$ radial distance (dimensionless)

$r_{w} \quad$ radius of the test interval (m)

$S_{e} \quad$ effective saturation in the relative permeability saturation relationship (dimensionless)

$S_{e c} \quad$ effective saturation in the capillary pressure saturation relationship (dimensionless)

$S_{g r} \quad$ residual gas saturation (dimensionless)

$S_{w} \quad$ water saturation (dimensionless)

$S_{w r} \quad$ minimum value of the water saturation achievable when gas displaces water (dimensionless)

$t \quad$ elapsed time (s)

$t_{D} \quad$ dimensionless time (dimensionless)

$\mathrm{V}_{\mathrm{i}} \quad$ test interval volume $\left(\mathrm{m}^{3}\right)$

$\mathrm{V}_{\text {DIS }} \quad$ volume of displaced water $\left(\mathrm{m}^{3}\right)$.

\section{INTRODUCTION}

Extended gas threshold pressure tests (EGTPT) have been successfully conducted to characterise the gas transport properties of candidate hostrock formations for the disposal of radioactive waste (e.g. Finsterle and Pruess, 1996; Senger et al., 1998). At the same time complementary research projects were initiated at the Grimsel test site, an underground rock laboratory in a fractured crystalline rock, to further develop the field equipment and optimise the in situ test procedures (Marschall et al., 1998; Croisé et al., 1998). The typical test procedure consisted of a hydraulic packer test 
under single-phase conditions (water) followed by a nitrogen gas injection at a constant rate and a final shut-in. The analysis of these tests was based on the conceptual framework of viscous capillary flow in a porous medium and allowed identifying characteristic behaviour of the gas pressure evolution when different two-phase flow models (i.e. capillary pressure - relative permeability - saturation relationships) were assumed.

A similar experimental procedure was adopted in 1997 for the characterisation of the gas transport properties of the Opalinus Clay formation at the Mont Terri rock laboratory (Thury and Bossart, 1999). The hydro- and gas tests were conducted in a vertical borehole which was equipped with a triple packer system. The test interval was placed at a depth between 9.10 and $13.60 \mathrm{~m}$ below ground level (Marschall et al., 2004). Possible crosshole responses could be monitored in two adjacent boreholes, each at a distance of about $1 \mathrm{~m}$. All boreholes were located in the shaly facies of the Opalinus Clay and intersected a sub-vertical tectonic feature, called "main fault" (reddish brown shading see Fig. 1). The combined hydro- and gas tests were part of a comprehensive site investigation programme, providing a detailed database for the hydraulic properties of the Opalinus Clay formation at Mont Terri. The hydraulic conductivity of the intact rock is very low and exhibits low spatial variability with a typical range of $10^{-14}-5 \times 10^{-13} \mathrm{~m} / \mathrm{s}\left(\sim 10^{-21}-5 \times 10^{-20} \mathrm{~m}^{2}\right)$. Significant enhancement of bulk permeability was not observed in zones with tectonic features such as the main fault. A synthesis of the hydrogeological investigations is provided in Croisé et al. (2004) and Marschall et al. (2004).

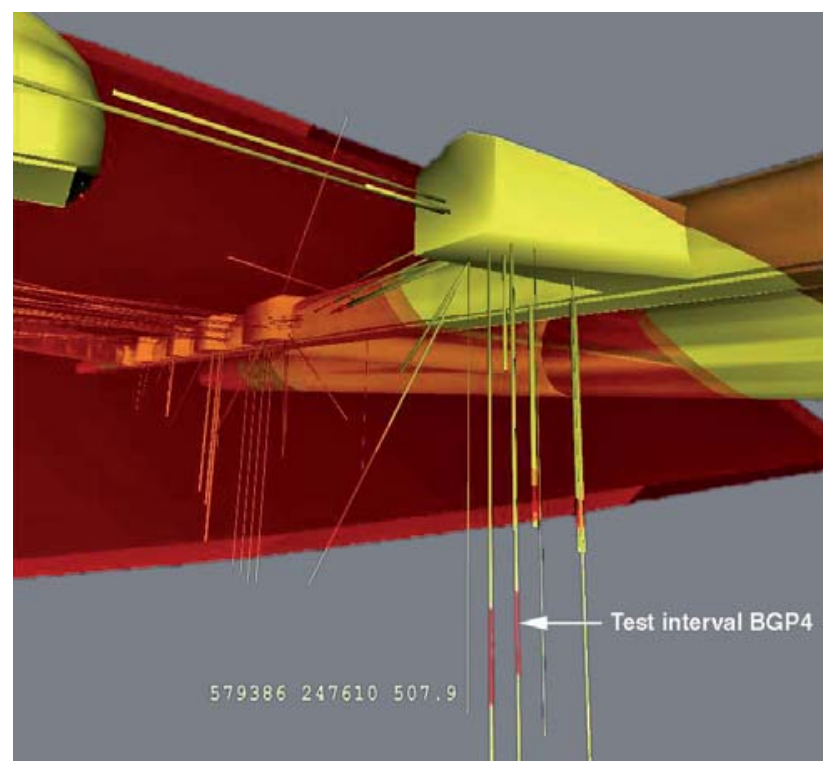

Figure 1

Location of borehole BGP4 in a 3-D image from the borehole information system of the Mont Terri Rock Laboratory (Heller and Jeannin, 2003).
The combined hydro- and gas test was conducted between 27 January 1997 and 2 June 1997 (Fig. 2). It consisted first of a series of water injection tests (constant rate RI and multistep constant pressure $\mathrm{HI}$ ) with flow periods of a few days and recovery periods of weeks to months (RIS/HIS). At the end of the water test (April 10), the water in the test interval was replaced by nitrogen (DIS) and a gas injection at a constant mass flow rate of $40 \mathrm{ml} / \mathrm{min}$ (GRI) was conducted over 18 hours (April 10 and 11). After a pressure of about $3 \mathrm{MPa}$ had been reached, a recovery phase (GRIS) was observed until June 2. The experimental data set for the gas test comprised:

- the pressure transients in the test interval;

- the displaced water volume in the test interval;

- and the nitrogen gas injection rate.

A detailed interpretation of the hydrotest prior to the EGTPT was performed in 1997 (summarised in Marschall et al., 2004). The analysis included an inverse parameter estimation approach and a comprehensive uncertainty analysis. The flow model used for the analysis was that of a radial homogeneous formation of infinite lateral extent with a constant wellbore storage. Darcy flow was assumed. The fitting parameters were hydraulic conductivity, specific storage, static formation pressure and wellbore storage. Uncertainties in these fitting parameters due to uncertainties in the non-fitting parameters (flow rates and borehole radius) were estimated. A very good match of the complete hydrotest sequence was obtained. The hydraulic conductivity was estimated to $2 \times 10^{-13} \mathrm{~m} / \mathrm{s}\left(\sim 2 \times 10^{-20} \mathrm{~m}^{2}\right)$ and the static formation pressure to $350 \mathrm{kPa}$, given a storage coefficient of $3 \times 10^{-5} \mathrm{~m}^{-1}$. It should be noted that no evidence for nonhydraulic processes (e.g. borehole closure due to creep) was found and the hydraulic parameters are very well constrained.

The subsequent interpretation of the EGTPT (summarised in Marschall et al., 2004) focussed on exploring the parameter range representative for the gas transport properties of the Opalinus Clay at Mont Terri. The analysis was performed in the framework of the generalised Darcy's law for multiphase flow and based on the concept of relative permeability and capillary pressure as functions of saturation (the so-called two-phase flow constitutive relationships). Inverse modelling of the pressure transients during the gas injection (GRI) and subsequent pressure recovery (GRIS) was performed by varying the permeability and the specific storage of the formation, the wellbore storage coefficient, the pseudo air entry pressure of the capillary pressure curve (Van Genuchten) and the porosity. The key results of the analysis were:

- The match obtained for the pressure transients of the gas test was very good. The permeability estimate was higher by a factor of 3 than that obtained from the hydrotest and the specific storage was lower by a factor of 10 . 

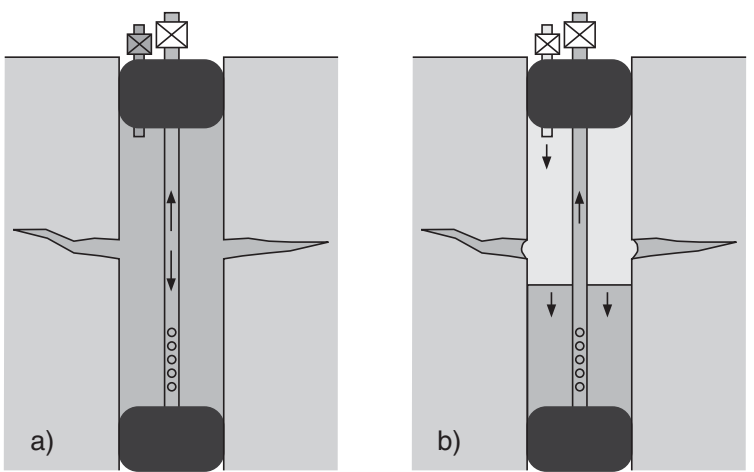

Valve closed

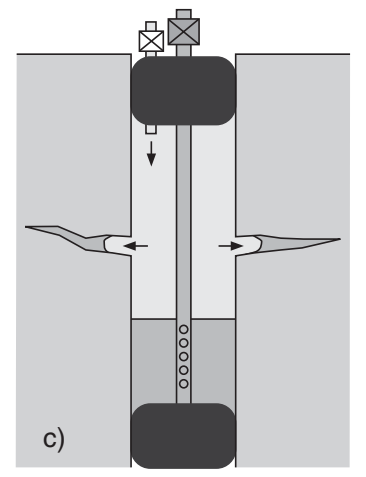

d)

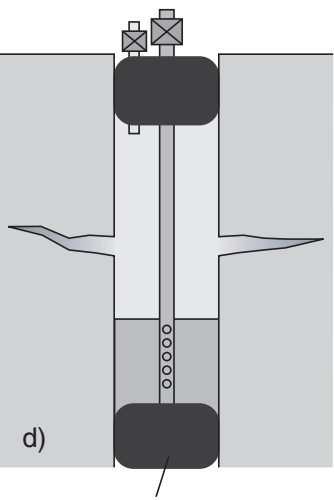

Packer

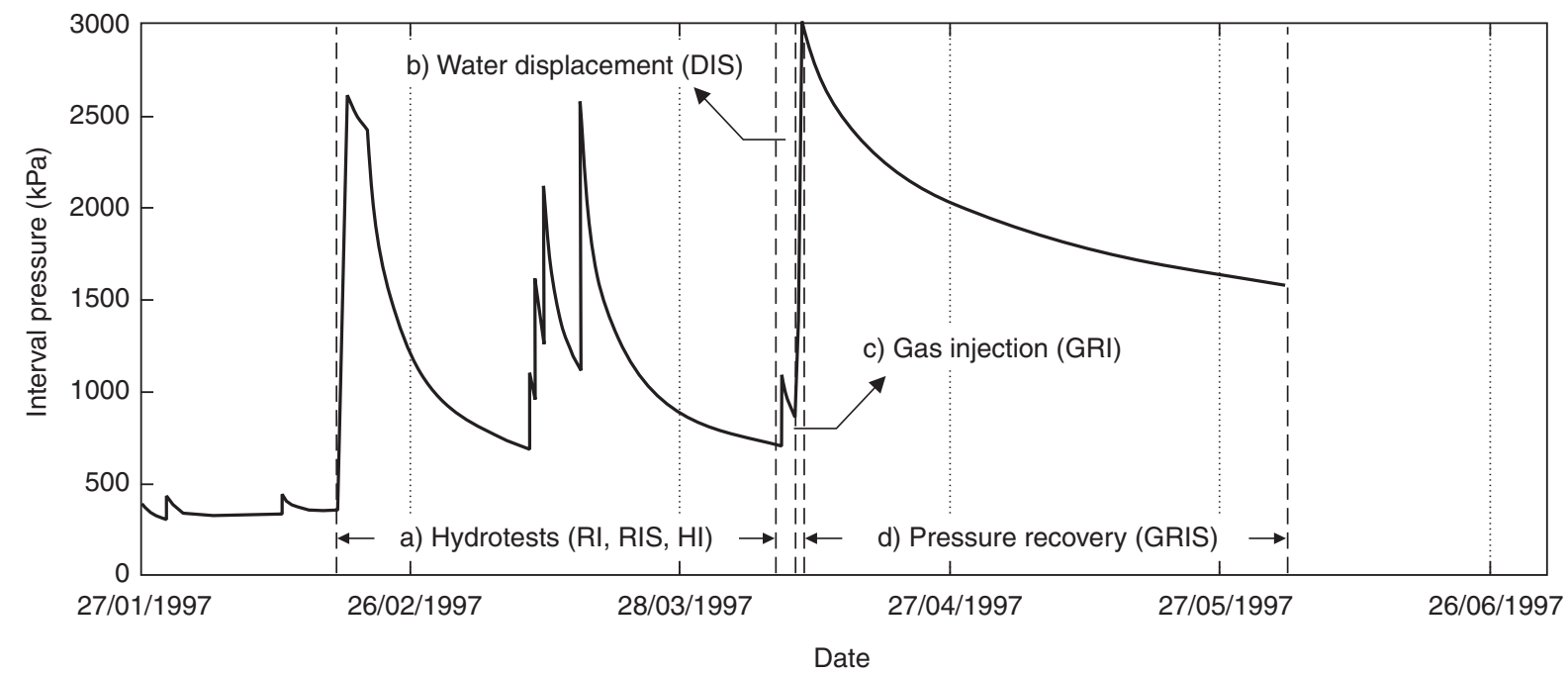

Figure 2

The extended gas threshold pressure test in borehole BGP4 at the Mont Terri Rock Laboratory (after Marschall et al., 2005): test sequences and evolution of interval pressure (RI - constant rate water injection, RIS - recovery period, HI - constant pressure water injection, DIS - water displacement, GRI - constant gas rate injection, GRIS - recovery period).

- No satisfactory fit could be obtained by fitting jointly the hydrotest and the gas test: the marked mismatch of the pressure recovery phases indicates that the model does not capture the overall system behaviour accurately (changes in storage and/or permeability).

- Considerable uncertainty ranges were determined for the air entry pressure: the air entry pressure estimates ranged between $400 \mathrm{kPa}$ (derived from the gas injection phase) and $850 \mathrm{kPa}$ (derived from the recovery phase).

The excellent fit of the pressure data led to the conclusion that the conceptual framework of two-phase flow is well suited to model the gas test. The estimated gas transport properties were largely consistent with the results gained from independent laboratory tests. On the other hand, the uncertainty ranges of the parameter estimates were rather high which was - at least partially - attributed to an insufficient numerical implementation of the gas/water exchange prior to the gas injection. Eventually, the inability to achieve a joint match of both hydrotest and gas test events gave rise to a comprehensive re-analysis of the test data which is described in this paper.

\section{BACKGROUND}

The re-analysis of the combined hydro- and gas test was, last but not least, motivated by the fact that the geoscientific database of the Opalinus Clay had been expanded considerably since the previous test interpretation. In particular, new laboratory data were available to better constrain the unknown parameters in the inverse modelling procedure. The objectives of the re-analysis of the EGTPT were to:

- reduce both conceptual uncertainties and parameter uncertainties by a joint match of both hydrotest and gas test events; 
- explore the potential of alternative two-phase flow constitutive relationships with focus on relative permeability as a function of saturation;

- optimise the design of future field experiments.

A brief summary of the conceptual framework on viscous capillary gas water flow is presented below. In particular, the two-phase flow constitutive relationships and their parameterisation are discussed.

The differential equation describing the two-phase incompressible one-dimensional radial flow of a wetting and a non-wetting fluid for a constant total flow rate $Q_{t}$ (sum of non-wetting and wetting phase flow rate: $Q_{t}=Q_{w}+Q_{n w}$ ) through a porous medium in the absence of gravity/buoyancy effects is given in hyperbolic form (Chen, 1988; Mc Whorter and Sunada, 1990). Note that if the compressibility of the phases were to be taken into account, the total flow rate $Q_{t}$ would no longer be independent of the radial distance, and the total pressure diffusion equation would also have to be solved (e.g. Peaceman, 1977). Another factor affecting the flow is the total diffusivity as a ratio of the permeability and the total compressibility.

$$
\Phi \cdot \frac{\partial S_{w}}{\partial t}=\frac{1}{r} \cdot \frac{\partial}{\partial r}\left[r \cdot D\left(S_{w}\right) \cdot \frac{\partial S_{w}}{\partial r}\right]-\frac{1}{r} \cdot\left[\frac{\mathrm{Q}_{t}}{2 \pi h} \cdot \frac{\partial f_{w}\left(S_{w}\right)}{\partial S_{w}}\right] \cdot \frac{\partial S_{w}}{\partial r}
$$

with the fractional flow for water (dimensionless, with $\left.Q_{w}=f_{w}\left(S_{w}\right) \times Q_{t}\right)$ :

$$
\mathrm{f}_{\mathrm{w}}\left(\mathrm{S}_{\mathrm{w}}\right)=\frac{1}{1+\frac{\mathrm{k}_{\mathrm{rnw}}\left(\mathrm{S}_{\mathrm{w}}\right) \cdot \mu_{\mathrm{w}}}{\mathrm{k}_{\mathrm{rw}}\left(\mathrm{S}_{\mathrm{w}}\right) \cdot \mu_{\mathrm{nw}}}}
$$

and the diffusion function $D\left(S_{w}\right)$ (note: $D\left(S_{w}\right)$ is positive as $P_{c}$ is a steadily decreasing function of $S_{w}$ ):

$$
D\left(S_{w}\right)=-f_{w}\left(S_{w}\right) \cdot \frac{k_{r n w} \cdot k}{\mu_{n w}} \cdot \frac{\partial P_{c}}{\partial S_{w}}
$$

The variables are: $t$, the elapsed time, $\Phi$, the porosity, $k_{r n w}$ and $\mu_{n w}, k_{r w}$ and $\mu_{w}$, the relative permeability and the viscosity of the non-wetting and of the wetting phase, respectively, $k$, the intrinsic permeability, $P_{c}$, the capillary pressure, and $h$, the length of the test interval (i.e. the distance between upper packer lower seal and lower packer upper seal).

Equation (1) can be written in dimensionless form as:

$$
\frac{\partial S_{w}}{\partial t_{D}}=\underbrace{\frac{1}{r_{D}} \frac{\partial}{\partial r_{D}}\left[r_{D} \cdot D_{D}\left(S_{w}\right) \cdot \frac{\partial S_{w}}{\partial r_{D}}\right]}_{\text {Diffusive part }} \cdot \underbrace{\frac{1}{r_{D}} \cdot\left[\frac{\partial f_{w}\left(S_{w}\right)}{\partial S_{w}}\right] \cdot \frac{\partial S_{w}}{\partial r_{D}}}_{\text {Advective part }}
$$

where all parameters are defined as dimensionless variables:

$$
\begin{array}{ll}
t_{D}=\frac{Q_{t} \cdot t}{2 \pi \mathrm{r}_{w}^{2} h \Phi} & \text { - dimensionless time, } \\
r_{D}=r / r_{w} & \text { - radial distance, } \\
S_{w} & \text { - water saturation, } \\
D_{D}\left(S_{w}\right)=\frac{2 \pi h}{Q_{t}} D\left(S_{w}\right) & \text { - dimensionless dispersion. }
\end{array}
$$

This normalised form of the two-phase flow equation makes clear that, during a gas injection test and under conditions where the pressure variations due to the compressibility of the gas phase can be neglected (e.g. during a constant pressure gas injection test), the advective-diffusive movement of the gas-water saturation front and, therefore, the pressure evolution depends on the following saturation dependent variables:

- For the advective part: on the derivative of the ratios of the relative permeabilities for water and non-wetting phase which is a function of the saturation.

- For the diffusive part: on the mobility ratio of the nonwetting and wetting phases (fractional flow function), the absolute value of the mobility of the non-wetting phase (relative permeability times the intrinsic permeability over the viscosity), the derivative of the capillary pressure as a function of saturation, and the total flow rate.

Following the parameterisation of Van Genuchten (1980), the capillary pressure as a function of the saturation reads:

$$
\begin{aligned}
& P_{c}=\frac{1}{a} \cdot\left(S_{e c}{ }^{n / 1-n}-1\right)^{1 / n} \\
& S_{e c}=\frac{S_{w}-S_{w r}}{1-S_{w r}}
\end{aligned}
$$

The residual saturation $S_{w r}$ is the minimum value of the water saturation achievable when gas is displacing water. The parameter $n$ is a pore size distribution index (shape factor). In the literature, the parameter $1 / \alpha$ is sometimes referred to as a "pseudo air entry pressure" for the gas phase.

Using the integral formulation of Mualem (1976), the relative permeability of the water $k_{r, w}$ and the gas phase $k_{r, g}$ can be defined as follows (van Genuchten, 1980; Parker et al., 1987):

$$
\begin{aligned}
& k_{r, w}=\left\{\begin{array}{c}
S_{e}^{\eta} \cdot\left(1-\left(1-S_{e}^{n / 1-n}\right)^{(n-1) / n}\right)^{2} \text { if } S_{w}<1-S_{g r} \\
\text { or } 1 \quad \text { if } S_{w} \geq 1-S_{g r}
\end{array}\right. \\
& S_{e}=\frac{S_{w}-S_{w r}}{1-S_{g r}-S_{w r}} \\
& k_{r, g}=\left(1-S_{e}\right)^{\gamma} \cdot\left[\left(1-S_{e}^{n / 1-n}\right)^{(n-1) / n}\right]^{2}
\end{aligned}
$$


$\eta$ and $\gamma$ are exponents describing the pore connectivity and the tortuosity of the porous medium and $S_{g r}$ is the residual gas saturation.

Enhancement (or reduction) of the gas mobility, as postulated in Marschall et al. (2004) for the interpretation of in-situ gas injection tests in low-permability claystone formations, can be taken into account by introducing a multiplication factor $f_{g}$ in the relative permeability equation, as follows:

$$
k_{r, g}=f_{g} \cdot\left(1-S_{e}\right)^{\gamma} \cdot\left[\left(1-S_{e}^{n / 1-n}\right)^{(n-1) / n}\right]^{2}
$$

In gas reservoirs or in fractured rock formations an enhanced gas mobility $\left(f_{g}>1\right)$ could be related to the Klinkenberg effect (effect of gas slippage on the pore walls, as suggested by $\mathrm{Li}$ and Horne, 2001). No experimental evidence exists for the occurrence of this process in tight claystone formations such as the Opalinus Clay.

Figure 3 presents the general shapes of the two-phase flow constitutive relationships. It introduces the following parameters:

- Residual gas saturation $S_{g r}$ : considering a drainage path (gas displacing water in a formation which is initially saturated), the residual gas saturation is a threshold value at which the gas starts to form a continuous phase and becomes mobile. On an imbibition path it is the gas which remains trapped within the pore network. In the present study no difference is made between the $S_{g r}$ values on the imbibition and drainage paths. Except for during the drilling phase (air drilling), the available experimental data are for the drainage path.

- Air entry pressure $P_{a e}$ : the Van Genuchten formulation for the capillary pressure does not take into account an air entry pressure, i.e. it is zero. In the approach as described in Dury et al. (1999), the air entry pressure is defined as the pressure at which the gas phase becomes mobile, i.e. at which the water saturation is less than $1-S_{g r}$.

Between 1997 and 2004, the bulk of the experimental work was carried out in the context of the Mont Terri project to characterise the geotechnical properties of the Opalinus Clay. Marschall et al. (2005) provide a survey of the rock properties which are relevant for gas transport processes in the Opalinus Clay; the key data are presented below.

Capillary pressure curves were measured on Opalinus Clay samples in the laboratory using different investigation techniques such as suction tests on core samples, water/ nitrogen adsorption and desorption (Nagra, 2002; Marschall et al., 2005). As shown in Figure 4, the spread between the different capillary pressure curves is significant and a clear hysteresis is seen between the wetting and drying paths (water adsorption/desorption). The authors fitted both desorption and adsorption data with a Van Genuchten

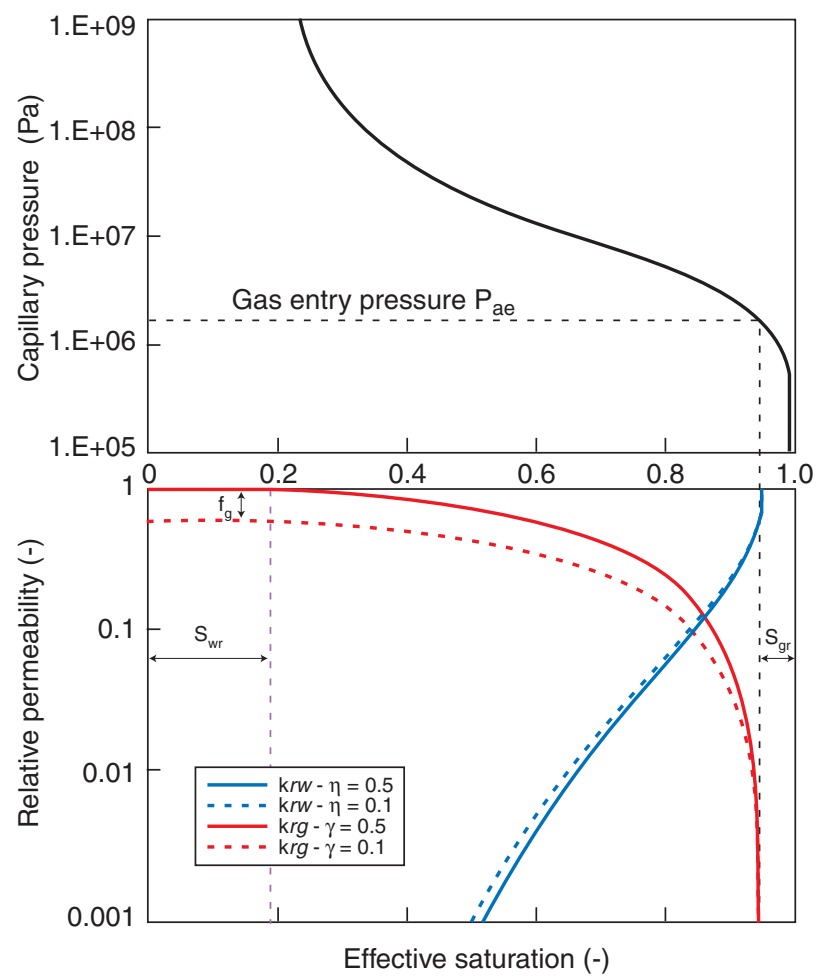

Figure 3

Two-phase flow capillary pressure and relative permeability functions as a function of the saturation (Van Genuchten Mualem type).

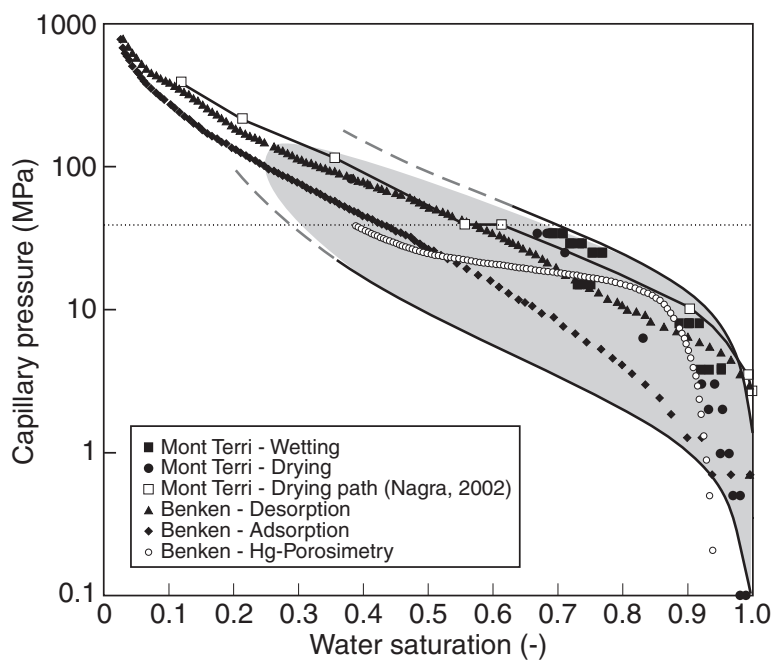

Figure 4

Capillary pressure curves as a function of the effective saturation, compiled for the Opalinus Clay (Marschall et al., 2005). A distinct difference in the shapes of the capillary pressure curves is observed for the drying and wetting path, respectively. The shaded area indicates the uncertainty range of the capillary pressure - saturation relationship for Opalinus Clay. 
function. The following fitting parameters are reported: residual gas saturation $S_{g r}=0.0$, pore size distribution index $n=1.6$ and the shape parameter $\alpha=0.065 \mathrm{MPa}^{-1}$ for desorption. The estimated parameters for the adsorption path are $S_{g r}=0.05, n=1.5$ and $\alpha=0.14 \mathrm{MPa}^{-1}$. The residual water saturation was treated as a non-fitting parameter (defined as $S_{w r}=0.0$ ). In the context of the present study, the desorption data are more relevant for the description of the gas imbibition process during the gas injection test.

The total porosity is well constrained and was determined with drying tests on samples. The resulting value of $16.2 \%$ is accepted for the present analysis.

\section{MODELLING APPROACH}

The general approach used to analyse the combined hydrotest and gas test in borehole BGP4 was as follows:

- Determine the conceptual models to be assessed.

- Provide initial values for fitting and non-fitting parameters.

- Specify constraints and an objective function and optimise fitting-parameter estimates using non-linear regression to obtain baseline estimates.

- Repeat the regression procedure using different conceptual models for various combinations of fitting parameters and investigate the uniqueness of the solution (check for local minima) by varying the initial values.

- Interpret the results of the multi-regression procedure by analysing the residuals (conceptual model uncertainty) and the joint-confidence regions (uncertainty of fitting parameters).

Conceptual model identification as the first step in the analysis procedure represents the greatest source of uncertainty in the parameter-estimation process. Parameter values estimated using inverse methods are strictly model related, i.e., changing the conceptual model can significantly change the estimated values of the fitting parameters. For the present study, the conceptual model was based on results of the former test analyses: the flow model is characterised by wellbore storage, a homogeneous formation and infinite lateral extent. The two-phase flow parametric model is based on Van Genuchten's formulation of capillary pressure and the Van Genuchten-Mualem formulation of relative permeability. The gas multiplication factor $f_{g}$ was introduced as an extension of the classical definition of relative gas permeability.

Initial values must be determined for two types of parameters, the non-fitting parameters (e.g., borehole radius, pressure history, injection rates, etc.) and fitting parameters (e.g., hydraulic conductivity, specific storage, two-phase flow parameters, etc.). The non-fitting parameter values were derived directly from field measurements, equipment configurations, laboratory measurements, etc. A careful review of the field logbook revealed some uncertainties with regard to the volume of water displaced during the DIS phase. These uncertainties are addressed in the present studies. Initial estimates of the fitting-parameter values were taken from the previous test analyses.

Setting up the inverse procedure consists of two steps: specifying constraints and choosing an objective function. The constraints are simply the different test events in terms of discrete pressure data to be matched by the fitting algorithm (non-linear regression). The intent is to select test sequences that maximise sensitivity to the different fitting parameters. In the present study the constraints were specified in the same way as in the previous analyses; the vast set of raw data was re-sampled to achieve reasonable parameter sensitivity for all fitting parameters of interest. Subsequently, an automated non-linear regression algorithm was used to satisfy the specified objective function, i.e., in the case of all the analyses in this study, to minimise the difference (residuals) between the measured and simulated data, expressed as the sum of the squared residuals.

The inverse procedure was set up for a series of runs (Table 1) addressing the parameters of the capillary pressure function (Series A) and the relative permeability relationship (Series B and C). Two different parametric models of relative permeability were tested, namely the classical Van Genuchten - Mualem model (Series A and B) and its extended formulation of relative gas permeability with the gas multiplication factor $f_{g}$ as given in Equation (11) (Series C).

The results from each inverse procedure include a simulation of the entire test sequence, a set of values for the fitting parameters, the residual errors (squared differences between observed and calculated values), the calculated jointconfidence regions and the correlation matrices for the fitting parameters. Diagnostic plots of the different test events were used to assess qualitatively how well the data match.

\section{MODELLING RESULTS}

The detailed analysis of the hydrotest sequence as described in Marschall et al. (2004) represented the starting point for this analysis of the gas test events. The hydraulic flow model (well-bore storage, homogeneous formation, infinite lateral extent) and the initial values of the hydraulic parameters were therefore taken from the previous study. A careful review of the field logbooks revealed that a major uncertainty of the gas injection sequence was related to the actual gas volume filled at the start of the injection. Previous analyses of the gas test had assumed a volume of 1.851 based on closed system considerations. The re-evaluation indicated a lower volume of about 1.651 as being more realistic and it also closely corresponds to the volume of water extracted during the DIS phase. Initial values of the gas related parameters were deduced from the compilation provided in Marschall et al. (2005). Table 2 gives an overview of the initial values of the 
TABLE 1

Overview of inverse runs with the conceptual assumptions, run identification and list of fitting parameters

\begin{tabular}{|c|c|c|}
\hline \multicolumn{3}{|c|}{ Inverse runs: Series A and B } \\
\hline \multirow[t]{3}{*}{ Conceptual assumptions } & Flow model & $\begin{array}{l}\text { Wellbore storage, homogeneous } \\
\text { formation, infinite lateral extent }\end{array}$ \\
\hline & Capillary pressure & Equation (9) \\
\hline & Relative permeability & Equation (10) \\
\hline \multirow[t]{7}{*}{ Inverse runs } & \multicolumn{2}{|c|}{ Fitting parameters } \\
\hline & $\mathrm{A} 1-\mathrm{A} 4$ & $1 / \alpha ; n$ \\
\hline & A5 & $1 / \alpha ; n, S_{w r}$ \\
\hline & B1 & $1 / \alpha ; \gamma$ \\
\hline & B2 & $\eta ; \gamma$ \\
\hline & B3 & $1 / \alpha ; n ; \eta ; \gamma$ \\
\hline & B5 & $k ; c_{O P A} ; c_{t z} ; \gamma$ \\
\hline \multicolumn{3}{|c|}{ Inverse runs: Series C } \\
\hline \multirow[t]{3}{*}{ Conceptual assumptions } & Flow model & $c f$. Series A and B \\
\hline & Capillary pressure & $c f$. Series A and B \\
\hline & Relative permeability & Equation (11) \\
\hline \multirow[t]{5}{*}{ Inverse runs } & \multicolumn{2}{|c|}{ Fitting parameters } \\
\hline & $\mathrm{C} 1$ & $\eta ; \gamma ; f_{g}$ \\
\hline & $\mathrm{C} 2$ & $1 / \alpha ; n ; \eta ; \gamma ; f_{g}$ \\
\hline & $\mathrm{C} 3$ & $1 / \alpha ; n ; S_{w r} ; \gamma ; f_{g}$ \\
\hline & $\mathrm{C} 4$ & $1 / \alpha ; n ; S_{w r} ; \gamma ; f_{g}$ \\
\hline
\end{tabular}

\section{TABLE 2}

Initial values of non-fitting and fitting parameters, based on previous analyses ( $c f$. Marschall et al., 2004)

\begin{tabular}{l|l}
\hline \multicolumn{2}{c}{ Test zone } \\
\hline Borehole radius & $r_{w}=0.043 \mathrm{~m}$ \\
Test interval length & $h=4.5 \mathrm{~m}$ \\
Test interval volume & $V_{i}=3.375 \times 10^{-3} \mathrm{~m}^{3}$ \\
Volume of displaced water & $V_{D I S}=1.65 \times 10^{-3} \mathrm{~m}^{3}$ (revised value) \\
Test zone compressibility & $c_{t z}=2 \times 10^{-8} \mathrm{~Pa}^{-1}$ \\
\hline
\end{tabular}

\begin{tabular}{l|l}
\hline \multicolumn{2}{c}{ Hydraulic hostrock properties } \\
\hline Intrinsic permeability & $k=1.5 \times 10^{-20} \mathrm{~m}^{2}$ \\
Static formation pressure & $P_{i}=352 \mathrm{kPa}$ \\
Rock compressibility & $c_{O P A}=1.03 \times 10^{-8} \mathrm{~Pa}^{-1}$ \\
Porosity & $\Phi=0.16$ \\
\hline \multicolumn{2}{c}{ Two-phase flow parameters } \\
\hline Pseudo air entry pressure & $1 / \alpha=20 \mathrm{MPa}$ \\
Pore distribution index & $n=1.6$ \\
Residual water saturation & $S_{w r}=0.0$ \\
Residual gas saturation & $S_{g r}=0.0$ \\
Relative permeability exponent & $\eta=0.333 ; \gamma=0.5$ \\
Gas multiplication factor & $f_{g}=1.0$ \\
\hline
\end{tabular}

key parameters as used in the present study. The relatively high test zone compressibility is most probably due to the equipment compliance.

The inverse runs of Series A concentrated on the estimation of the characteristic parameters of the capillary pressure function (pseudo air entry pressure $1 / \alpha$, pore size distribution index $n$ and residual water and gas saturation $S_{w r}$ and $S_{g r}$ ). For this purpose $1 / \alpha$ and $n$ were defined as fitting parameters and the inverse runs A1 to A4 were started for a range of residual gas and water saturations ( $c f$. Table 3 ). In run $\mathrm{A} 5$, another non-fitting parameter was added.

The results of the inverse runs are presented in Figure 5 with the overall fit of the entire test sequence, a magnification of the gas test sequence and a plot of the squared residuals. A further qualitative measure of the goodness of fit for both the hydrotest and the gas test sequence is given in the right-most column of Table 3 , representing the sum of squared residuals for each test phase.

The overall match of the data is remarkable for all runs of Series A. Slight deviations between data and simulations are observed only in the late times of the GRIS phase. Run A2 with low values of residual gas and water saturation $\left(S_{w r}=0\right.$, $\left.S_{g r}=0.001\right)$ seems to perform slightly better than the other 
TABLE 3

Summary of the results of inverse modelling including run identifications, best fitting parameters and the sum of squared residuals as an indicator for the overall quality of fit

\begin{tabular}{|c|c|c|}
\hline \multicolumn{3}{|c|}{ Inverse runs: Series A } \\
\hline Run ID & Fitting parameter (best fit) & Sum of squared residuals $\left(10^{6} \mathrm{~Pa}^{2}\right)$ \\
\hline $\begin{array}{l}\mathrm{A} 1 \\
S_{w r}=0, S_{g r}=0.003\end{array}$ & $\begin{array}{l}1 / \alpha=7.5 \mathrm{MPa} \\
\mathrm{n}=1.60\end{array}$ & $\begin{array}{l}\text { Hydrotest: } 6.1 \times 10^{3} \\
\text { Gas test: } 1.0 \times 10^{5}\end{array}$ \\
\hline $\begin{array}{l}\mathrm{A} 2 \\
S_{w r}=0, S_{g r}=0.001\end{array}$ & $\begin{array}{l}1 / \alpha=8.5 \mathrm{MPa} \\
n=1.61\end{array}$ & $\begin{array}{l}\text { Hydrotest: } 6.1 \times 10^{3} \\
\text { Gas test: } 1.0 \times 10^{5}\end{array}$ \\
\hline $\begin{array}{l}\mathrm{A} 3 \\
S_{w r}=0.36, S_{g r}=0.001\end{array}$ & $\begin{array}{l}1 / \alpha=9.0 \mathrm{MPa} \\
n=1.63\end{array}$ & $\begin{array}{l}\text { Hydrotest: } 6.1 \times 10^{3} \\
\text { Gas test: } 1.4 \times 10^{5}\end{array}$ \\
\hline $\begin{array}{l}\mathrm{A} 4 \\
S_{w r}=0.36, S_{g r}=0.003\end{array}$ & $\begin{array}{l}1 / \alpha=9.4 \mathrm{MPa} \\
n=1.60\end{array}$ & $\begin{array}{l}\text { Hydrotest: } 6.1 \times 10^{3} \\
\text { Gas test: } 2.0 \times 10^{5}\end{array}$ \\
\hline A5 & $\begin{array}{l}1 / \alpha=9.3 \mathrm{MPa} \\
n=1.64 \\
S_{w r}=0.18\end{array}$ & $\begin{array}{l}\text { Hydrotest: } 6.4 \times 10^{3} \\
\text { Gas test: } 1.1 \times 10^{5}\end{array}$ \\
\hline \multicolumn{3}{|c|}{ Inverse runs: Series B } \\
\hline $\begin{array}{l}\mathrm{B} 1 \\
S_{w r}=0.0, S_{g r}=0.001\end{array}$ & $\begin{array}{l}1 / \alpha=4.6 \mathrm{MPa} \\
\gamma=0.48\end{array}$ & $\begin{array}{l}\text { Hydrotest: } 6.1 \times 10^{3} \\
\text { Gas test: } 9.4 \times 10^{4}\end{array}$ \\
\hline $\mathrm{B} 2$ & $\begin{array}{l}\eta=0.30 \\
\gamma=0.19\end{array}$ & $\begin{array}{l}\text { Hydrotest: } 6.1 \times 10^{3} \\
\text { Gas test: } 1.4 \times 10^{5}\end{array}$ \\
\hline B3 & $\begin{array}{l}1 / \alpha=12 \mathrm{MPa} \\
n=1.49 \\
\eta=0.41 \\
\gamma=0.41\end{array}$ & $\begin{array}{l}\text { Hydrotest: } 6.1 \times 10^{3} \\
\text { Gas test: } 1.2 \times 10^{5}\end{array}$ \\
\hline B5 & $\begin{array}{l}k=2.3 \times 10^{-20} \mathrm{~m}^{2} \\
c_{O P A}=5.8 \times 10^{-9} \mathrm{~Pa}^{-1} \\
c_{t z}=2.8 \times 10^{-8} \mathrm{~Pa}^{-1} \\
\gamma=0.20\end{array}$ & $\begin{array}{l}\text { Hydrotest: } 3.1 \times 10^{4} \\
\text { Gas test: } 4.1 \times 10^{4}\end{array}$ \\
\hline \multicolumn{3}{|c|}{ Inverse runs: Series C } \\
\hline $\mathrm{C} 1$ & $\begin{array}{l}\eta=0.06 \\
\gamma=0.18 \\
f_{g}=1.0\end{array}$ & $\begin{array}{l}\text { Hydrotest: } 6.4 \times 10^{3} \\
\text { Gas test: } 1.4 \times 10^{5}\end{array}$ \\
\hline $\mathrm{C} 2$ & $\begin{array}{l}1 / \alpha=5.7 \mathrm{MPa} \\
n=1.7 \\
\eta=0.73 \\
\gamma=0.38 \\
f_{g}=1.1\end{array}$ & $\begin{array}{l}\text { Hydrotest: } 6.4 \times 10^{3} \\
\text { Gas test: } 9.5 \times 10^{4}\end{array}$ \\
\hline C3 & $\begin{array}{l}1 / \alpha=4.6 \mathrm{MPa} \\
n=1.54 \\
S_{w r}=0.38 \\
\gamma=0.4 \\
f_{g}=0.44\end{array}$ & $\begin{array}{l}\text { Hydrotest: } 6.4 \times 10^{3} \\
\text { Gas test: } 9.3 \times 10^{4}\end{array}$ \\
\hline $\mathrm{C} 4$ & $\begin{array}{l}1 / \alpha=9.0 \mathrm{MPa} \\
n=1.67 \\
S_{w r}=0.26 \\
\gamma=0.4 \\
f_{g}=1.05\end{array}$ & $\begin{array}{l}\text { Hydrotest: } 6.4 \times 10^{3} \\
\text { Gas test: } 1.1 \times 10^{5}\end{array}$ \\
\hline
\end{tabular}


simulations. The estimated $1 / \alpha$ value ranges between 7.5 and 9.4 $\mathrm{MPa}$ and the pore size distribution index is very stable with values of 1.59 to 1.64 . On the other hand, the graph of the residuals in Figure 5 exhibits an increasing mismatch in the late times of the GRIS phase, indicating that the implemented conceptual assumptions (two-phase flow parametric models) do not fully account for the gas pressure dissipation in the test interval after the shut-in.

Further, two-phase flow constitutive relationships were explored in the inverse runs of Series B. The exponents $\eta$ and $\gamma$ of the relative permeability function were defined as additional fitting parameters in runs B1 to B3. A complementary run $\mathrm{B} 5$ was performed with the intrinsic permeability $k$, rock compressibility $c_{O P A}$ and test zone compressibility $c_{t z}$ as auxiliary fitting parameters.
The additional degree of freedom achieved by introducing the $\gamma$ parameter improves the match considerably (Fig. 5). In particular, it is run B1 which simulates the GRIS phase nearly perfectly. The fit of the GRI phase is just as excellent and in the late times of GRIS the residuals exhibit a clear tendency to stabilise at a low level of deviation. The estimated pseudo entry pressure of $4.6 \mathrm{MPa}$ is somewhat lower than in Series A, but undoubtedly in the range of expectation (Fig. 4). The estimated $\gamma$ value is 0.48 .

The intention of run B5 was to test whether the joint inversion of the hydro- and gas test sequences with a combination of hydraulic and gas parameters ( $c f$. Table 3) could improve the fitting process. The match of the data is not satisfactory: it is true that the fit of the gas phase is acceptable, but the hydrotest phase is worsened considerably
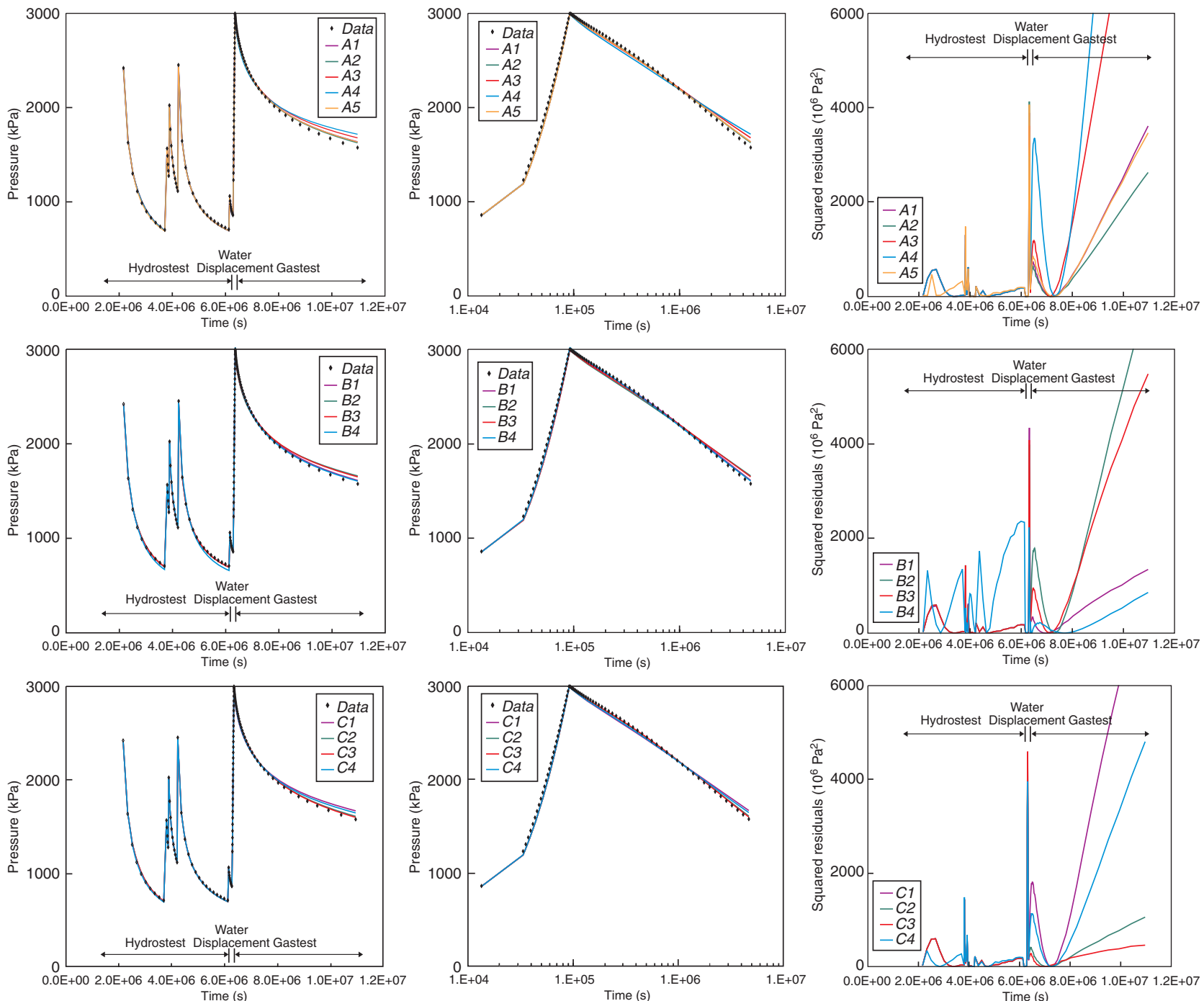

Figure 5

Inverse modelling of the extended gas threshold pressure test in BGP4: overall match of the entire test sequence (first column), magnification of the gas event (second column) and graphs of the residuals (last column). 

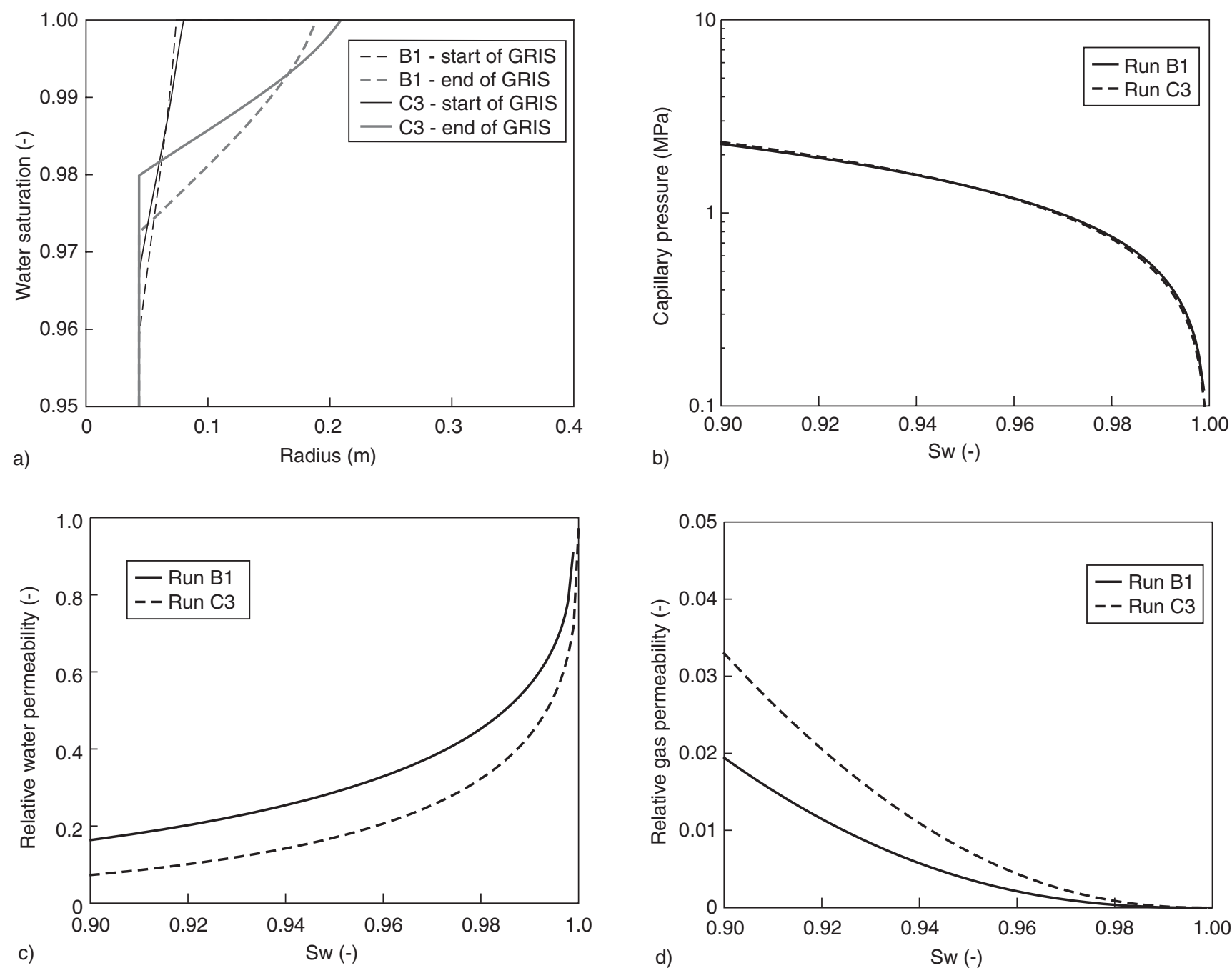

Figure 6

Comparison of the best matching runs B1 and C3: a) radial saturation profiles; b) capillary pressure $v s$. water saturation; c) relative water permeability and d) relative gas permeability $v s$. saturation.

as is seen in the graph of the residuals in Figure 5. The results indicate that the risk of being trapped in a local minimum of the objective function is considerably higher when a joint inversion strategy is used, whereas a sequential inversion allows for a more focussed estimation of those fitting parameters which are most sensitive to the individual test events.

The definition of Series $\mathrm{C}$ was motivated by the fact that the previous analysis of the gas test suggested a slightly higher intrinsic permeability than the hydrotest analysis (Marschall et al., 2004). For this reason the gas multiplication factor was introduced as a parameter which decouples relative gas and water permeabilities. The overall match of all runs of Series $\mathrm{C}$ is excellent and the differences between the simulations are largely restricted to the late times of the GRIS event (cf. Fig. 5). As seen in the plot of the residuals, run $\mathrm{C} 3$ performs better than the other runs, in particular because the residuals stabilise at low values during the late GRIS phase. The pseudo entry pressure, pore size distribution coefficient and gas permeability exponent $\gamma$ are similar to the best estimates of run B1, the gas multiplication factor is 0.44 . On the other hand, the analysis of the covariance matrix exhibits a high correlation between the different fitting parameters, indicating that the parameters are not independent of each other. The highest covariance coefficients were determined for the parameter combinations $1 / \alpha-n$ and $\gamma-n$.

It is worth mentioning that the estimated two-phase flow parameters are representative for the immediate rock zone around the borehole. The inverse runs indicate that the radial extension of the partly desaturated area resulting from the gas injection during the GRI and GRIS event is not larger than about $0.20 \mathrm{~m}$ from the midpoint of the borehole (Fig. 7a). 

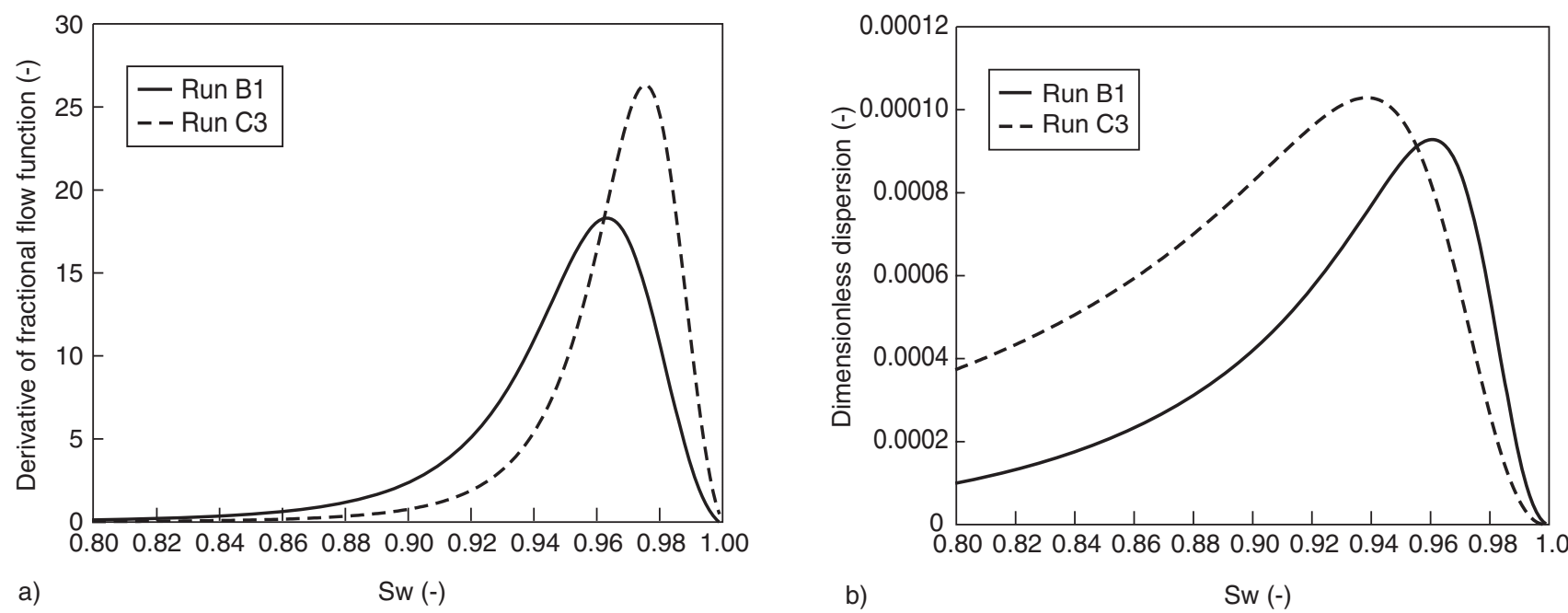

Figure 7

Fractional flow and diffusion function for the best matching runs B1 and C3.

Figure 6a shows the radial water saturation profiles at the beginning and at the end of the GRIS phase for the inverse runs $\mathrm{B} 1$ and $\mathrm{C} 3$. Even in this narrow zone around the borehole the water saturation remains high at values $>0.96$.

An overall comparison of the results of the 3 series of inverse runs provides rather consistent parameter estimates for the capillary pressure curve: the estimates of the pseudo entry pressure range between 4.6 and $12 \mathrm{MPa}$, the pore size distribution index varies between 1.5 and 1.7. In particular runs $\mathrm{B} 1$ and $\mathrm{C} 3$ with the best data matches provide nearly identical parameters of the capillary pressure curve (Fig. 6b). The characterisation of the relative permeability relationship seems to be more uncertain: the best estimates of the exponents $\eta$ and $\gamma$ of the relative permeability function are generally in the ranges $0.18 \leq \gamma \leq 0.48$ and $0.30 \leq \eta \leq 0.73$. The residual gas saturation is well bracketed $0 \leq S_{g r} \leq 0.003$, whereas the best estimates of the residual water saturation exhibit a larger variation $0 \leq S_{w r} \leq 0.36$. Figures $6 \mathrm{c}$ and $6 \mathrm{~d}$ show the relative permeability functions of the best fitting runs $\mathrm{B} 1$ and $\mathrm{C} 3$ in the range of high water saturation $0.9 \leq S_{w} \leq 1$. In this saturation range, the differences between the two parametric models are not very distinct. Therefore, it is not possible to identify the model concept with the best overall performance. It is very probable that other parameter sets, such as another combination of residual water saturation and gas multiplication factor, could produce relative permeability functions which are indistinguishable in the high saturation range. This behaviour is essentially expressed by the strong correlation of the fitting parameters.

Given the fact that high covariance coefficients were determined for most of the combinations of fitting parameters, it may be more appropriate to present the twophase flow parameters in terms of the fractional flow $f_{w}$ and dimensionless dispersion function $D_{D}$ as defined in Equations (2) and (8). The derivative of the fractional flow function $\partial f_{w} / \partial S_{w}$ describes the advective component of the saturation front (Eq. (4)) and $D_{D}$ characterises the diffusive part. Figure 7 shows the two dimensionless functions $\partial f_{w} / \partial S_{w}$ and $D_{D}$ for the best fitting runs B1 and C3. The comparison of $\partial f_{w} / \partial S_{w}$ indicates for run $\mathrm{C} 3$ a faster propagation of the saturation front at high water saturations $\left(S_{w}>0.96\right)$ which is slowed down significantly at lower saturations. Correspondingly, the dispersion functions exhibit a characteristic behaviour: for water saturations above 0.96 the dispersion function of the parameter set of run $\mathrm{C} 3$ is higher than for run $\mathrm{B} 1$, whereas for saturations below 0.95 , simulation $\mathrm{C} 3$ is characterised by a significantly lower spread of the saturation front. The characteristic signatures of both the fractional flow function and the diffusion function suggest that the two competing model concepts for the relative gas permeability according to Equations (10) and (11) might be distinguished, if the water displacement in the rock formation covers a wider range of water saturation.

\section{OPTIMISATION OF EXPERIMENTAL DESIGN}

The experimental data obtained during the gas threshold pressure tests did not allow a clear discrimination between the two different parameterisations of gas permeability according to Equations (10) and (11). Furthermore, the adjacent observation boreholes could not be used as independent evidence for model discrimination, because the gas saturation levels and the pore pressure perturbation in the rock formation were too low to be detected in a crosshole configuration. For this reason, complementary design calculations were conducted to assess the distinguishing 
power that can be achieved with an optimisation of the gas test procedure and improvement of the site instrumentation. The basic optimisation issues were:

- Significant extension of the gas injection phase, using a constant pressure event instead of constant rate event.

- Assuming the availability of crosshole observations, allowing for the determination of the spatial propagation of the pressure and saturation front.

The potential benefit of an extended gas injection phase was tested using the parameter sets corresponding to the inverse runs B1 and C3. The assumed test procedure was a long lasting constant pressure injection event (test duration 5 years; interval pressure $2 \mathrm{MPa}$ above static formation pressure). The modelling output consisted of the transient gas injection rate, saturation profiles and pore pressure profiles in the vicinity of the test interval.

Figure 8a shows the comparison of the gas flow rates in a cartesian plot. The overall shape of the transients is similar for both cases with a steep drop of the gas flow rate in the early times (0-100 days) and a flat decline in the late times (>300 days). The slopes of the late time responses are identical but the injection rates are about $20 \mathrm{ml} / \mathrm{min}$ higher for case B1. Differences in gas flow rate in the order of $20 \mathrm{ml} / \mathrm{min}$ can be resolved easily with standard gas flow meters. Consequently, the gas flow rates of the late time period could help to distinguish between the competing model concepts.

The evolution of the radial saturation profiles is shown in Figure 8b. Notably, in both cases the gas front moves very slowly and reaches a distance of about $0.8 \mathrm{~m}$ after 5 years of gas injection. The water saturation of the rock around the boreholes remains at a high level of $S_{w}>0.95$ during the entire test period. The closer comparison of the two cases, however, shows slight differences in the evolution of the gas front. While the saturation fronts of case B1 and C3 are essentially indistinguishable during the first 60 days, a progressive separation is observed in the late times (1 year, 5 years). The propagation of the saturation front is faster in case $\mathrm{C} 1$, whereas the degree of desaturation in the immediate vicinity around the borehole is higher in case B1. From a practical perspective, it seems difficult to detect such small changes in water saturation with crosshole observations. The changes in water content are too small to be resolved in a satisfactory manner and the instrumentation of a nearby borehole with appropriate equipment (e.g. psychrometer, time domain reflectometer) could distort the conditions around the injection borehole significantly. On the other hand, complementary instrumentation of the injection borehole seems feasible. Comprehensive experience in measuring water saturation around a microtunnel (diameter $1 \mathrm{~m}$ ) was made in the context of the ventilation experiment at the Mont Terri rock laboratory (EURATOM, 2006).

The pore water pressure profiles in Figure $8 \mathrm{c}$ show that a very small, but detectable pore pressure perturbation
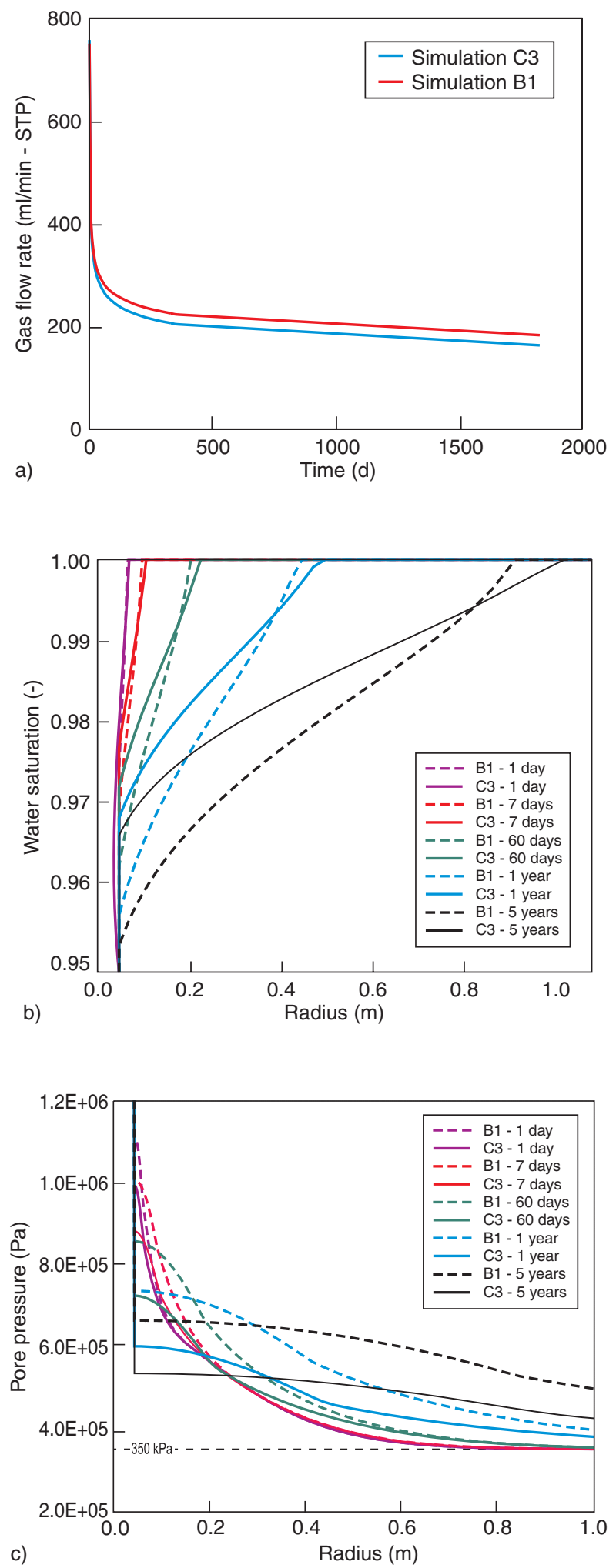

Figure 8

Design calculations of a longterm constant pressure gas injection test, based on the estimated two-phase flow parameters of simulations B1 and C3: a) gas flow rate, b) water saturation profiles and c) pressure profiles. 
(> $4 \mathrm{kPa}$ ) develops after 2 months at a radial distance of $1 \mathrm{~m}$ from the test interval. After 1 year the pressure change is much more significant with magnitudes in the order of $50 \mathrm{kPa}$ above static formation pressure (at a distance of $1 \mathrm{~m}$ ). The discriminative power of crosshole pressure observations is limited: for case B1 the magnitude of the pore pressure perturbation is slightly higher than for case $\mathrm{C} 3$ but the shape of the pressure front is similar. This is because the pore pressure evolution is mainly affected by the hydraulic properties of the saturated rock. Crosshole pressure observations are therefore appropriate for constraining the hydraulic properties (hydraulic diffusivity and conductivity).

The results of the design calculations suggest that a gas injection test should be conducted for a period of 1 year or longer. However, even such a long test could not distinguish competing two-phase flow conceptual models in great detail, because the desaturation of the rock during the gas injection phase is quite limited. Complementary instrumentation of the test interval with equipment that can detect changes in water saturation around the borehole would provide independent evidence to better constrain the inverse problem. Further evidence is expected from complementary laboratory experiments which can be conducted for a wider spectrum of water saturation ( $c f$. Marschall et al., 2005).

\section{CONCLUSIONS}

An extended gas threshold pressure test, consisting of a multistage hydrotest sequence and a gas injection phase, was conducted in the Opalinus Clay formation of the Mont Terri rock laboratory. The test interpretation was carried out through an inverse modelling approach, using the multiphase simulator TOUGH2/iTOUGH2. Complementary laboratory data were considered in the test interpretation procedure, such as porosity estimates and capillary pressure measurements. The constraining power of these independent data led to a significant improvement in the consistency between singlephase hydraulic parameters and two-phase flow parameters.

The emphasis of the inverse modelling was on the applicability of classical two-phase flow constitutive relationships (capillary pressure and relative permeability relationships) for the simulation of the gas test sequence. The capillary pressure function was based on Van Genuchten's formulation and the relative permeability relationships were of the Van Genuchten - Mualem type.

Summarising the results of this study, the following conclusions can be drawn:

- An excellent overall fit of both the hydrotest and the gas test sequences was achieved with a single parameter set (single-phase and two-phase flow parameters). The estimated intrinsic permeability of $1.5 \times 10^{-20} \mathrm{~m}^{2}$ matches both test sequences. The consistency of single-phase and two-phase flow simulations suggests that the concept of two-phase flow in porous media is appropriate for modelling gas transport in Opalinus Clay.

- The applicability of Van Genuchten's formulation of the capillary pressure function was confirmed and the corresponding parameters were bracketed. The best estimates for the pseudo entry pressure $1 / \alpha$ range between 4.6 and $12 \mathrm{MPa}$; based on the best fitting inverse runs the recommended value is $4.6 \mathrm{MPa}$. The estimated pore size distribution factor $n$ varies between 1.5 and 1.7. The results are consistent with independent laboratory data ( $c f$. Fig. 4).

- Relative gas/water permeability was parameterised according to the Van Genuchten - Mualem formulation (parameters: $S_{w r}, S_{g r}, n$, exponents $\eta$ and $\gamma$ ). Strong correlations of the different fitting parameters affected the inverse modelling procedure. Consequently, the parameter estimates exhibit a considerable degree of uncertainty: The best estimates of the exponents $\eta$ and $\gamma$ of the relative permeability function are in the ranges $0.18 \leq \gamma \leq 0.48$ and $0.30 \leq \eta \leq 0.73$. The residual gas saturation is well bracketed $0 \leq S_{g r} \leq 0.003$, whereas the best estimates of the residual water saturation exhibit are larger variation $0 \leq S_{w r} \leq 0.36$.

- An extension of the Van Genuchten - Mualem formulation was tested, which introduces a gas multiplication factor for the relative gas permeability. With the given data set it was not possible to determine whether this extension performs better than the classical formulation of relative permeability.

- The distinguishing power of gas threshold pressure tests with regard to the identification of relative permeability models could be improved by extending the gas injection phase. The design calculations suggest that gas injection tests with an injection period in the order of 1 year (and more) are needed to better constrain the gas permeability models. Complementary borehole instrumentation for the detection of the desaturation front could further improve the data analysis. Such refined gas tests can be conducted in the context of underground rock laboratories, where the infrastructure for well-controlled longterm testing is available.

- Gas permeability tests on core specimen can provide further insight on gas transport mechanisms of ultra-low permeability formations such as Opalinus Clay, because such tests can be run for a wider spectrum of water saturations.

\section{ACKNOWLEDGEMENTS}

The authors would like to thank research collaborators and project partners, especially Rainer Senger (Intera), E. Wyss (Solexperts) and P. Bossart (Geotechnical Institute Berne), who have contributed to the in-situ testing campaign and the early test interpretation. 


\section{REFERENCES}

Chen, Z.X. (1988) Some invariant solutions to two-phase fluid displacement problems including capillary effect. Soc. Petrol. Eng. Reservoir Eng., 3, 691-700.

Croisé, J., Marschall, P. and Senger, R. (1998) Gas-water flow in a shear zone of a granitic formation: Interpretation of field experiments. DisTec'98-International Conference on Radioactive Waste Disposal, Hamburg, Germany, 668.

Croisé, J., Schlickenrieder, L., Marschall, P., Boisson, J.Y., Vogel, P. and Yamamoto, S. (2004) Hydrogeological investigations in a low permeability claystone formation: the Mont Terri rock laboratory. Phys. Chem. Earth, 29, 3-15.

Dury, O., Fischer, U. and Schulin, R. (1999) A comparison of relative nonwetting-phase permeability models. Water Resour. Res. 35/5, 1481-1493.

EURATOM (2006) Ventilation experiment in Opalinus Clay for the disposal of radioactive waste in underground repositories. Final Technical Report FIS5-2001-00015, European Community - Programme 1998-2002, Brussels, Belgium (in press).

Finsterle, S. and Pruess, K. (1996) Design and analysis of a well test for determining two-phase hydraulic properties. Report $L B N L$ 39620, Lawrence Berkeley National Laboratory, Berkeley, Calif., December 1996.

Heller, M. and Jeannin, P.Y. (2003) Développements en matière de SIG et de visualisation 3D à l'ISSKA, Stalactite 2/2003.

Li, K. and Horne, R.N. (2001) Gas slippage in two-phase flow and the effect of temperature. SPE paper 68778.

Marschall, P., Croisé, J., Fischer, U., Senger, R. and Wyss, E. (1998) Gas flow through water-saturated shear zones: Field- and laboratory experiments and their interpretation. Mat. Res. Soc. Symp. Proc., 506, 741-748.

Marschall, P., Croisé, J., Schlickenrieder, L., Boisson, J.Y., Vogel, P. and Yamamoto, S. (2004). Synthesis of hydro- geological investigations at Mont Terri site (Phases 1 to 5). Report of the FOWG, Série Géologie No. 6, Bern, 7-92.

Marschall, P., Horseman, S. and Gimmi, T. (2005) Characterisation of gas transport properties of the Opalinus Clay, a potential host rock formation for radioactive waste disposal. Oil Gas Sci. Technol., 60, 1, 2, 2005.

Mc Whorter, D.B. and Sunada, D.K. (1990) Exact integral solutions for two-phase flow. Water Resour. Res., 26, 399-413.

Mualem, Y. (1976) A new model for predicting the hydraulic conductivity of unsaturated porous media. Water Resour. Res., 12, 513-522.

Nagra (2002) Projekt Opalinuston - Synthese der geowissenschaftlichen Untersuchungsergebnisse. Entsorgungsnachweis für abgebrannte Brennelemente, verglaste hochaktive sowie langlebige mittelaktive Abfälle. Nagra Technical Report NTB 02-03, Nagra, Wettingen, Switzerland.

Parker, J.C., Lenhard, R.J. and Kuppusamy, T. (1987) A parametric model for constitutive properties governing multiphase flow in porous media. Water Resour. Res., 23, 618-624.

Peaceman, D.W. (1977) Fundamentals of Numerical Reservoir Simulation. Elsevier, 176 p.

Senger, R., Marschall, P. and Lavanchy, J.M. (1998) Gas threshold pressure tests in deep boreholes for determining twophase flow properties of the host rock at the proposed L/ILW repository, Switzerland. Mat. Res. Soc. Symp. Proc., 506, 829838.

Thury, M. and Bossart, P., eds. (1999) Mont Terri Rock Laboratory: Results of the Hydrogeological, Geochemical, and Geotechnical Experiments Performed in 1996 and 1997. Bern, Switzerland, Landeshydrologie und -geologie, Geologische Berichte Nr. 23.

Van Genuchten, M.Th. (1980) A closed-form equation for predicting the hydraulic conductivity of unsaturated soils. Soil Sci.Soc.Am.J., 44.

Final manuscript received in January 2006

Copyright $(\mathbb{C} 2006$ Institut français du pétrole

Permission to make digital or hard copies of part or all of this work for personal or classroom use is granted without fee provided that copies are not made or distributed for profit or commercial advantage and that copies bear this notice and the full citation on the first page. Copyrights for components of this work owned by others than IFP must be honored. Abstracting with credit is permitted. To copy otherwise, to republish, to post on servers, or to redistribute to lists, requires prior specific permission and/or a fee: Request permission from Documentation, Institut français du pétrole, fax. +33147527078 , or revueogst@ifp.fr. 